AT-TAJDID: Jurnal Pendidikan Dan Pemikiran Islam

(p-ISSN: 2548-5784 le-ISSN: 2549-2101)

Vol. (04 ) (02), (Desember) (2020), (Halaman) (133-139)

Doi: http://dx.doi.org/10.24127/att.v4.i02.1417

\title{
BIMBINGAN KONSELOR BAGI ORANG TUA ANGKAT ANAK TERLANTAR ANAK TERLANTAR (STUDI KASUS DI DINAS SOSIAL KOTA BANDAR LAMPUNG)
}

\author{
Winda Sabrina ${ }^{1}$ \\ Universitas Islam Negeri Sunan Kalijaga Yogyakarta \\ Windasabrina658@gmail.com \\ Dwi Noviatul Zahra ${ }^{2}$ \\ Program Doktor Universitas Negeri Sunan Kalijaga Yogyakarta \\ dwinoviatulzahra11@gmail.com
}

\begin{abstract}
ABSTRAK
Bimbingan konselor adalah salah satu cara yang dilakukan pemerintah dalam pemberian bantuan kepada calon orang tua angkat yang akan mengangkat anak dengan cara berdialog, memberikan motivasi untuk menemukan jalan keluar dan mencapai tujuan yang diinginkan Penelitian ini dilakukan karena dilatarbelakangi oleh banyaknya masalah yang timbul saat proses pengangkatan anak dan masalah pribadi yang dihadapi oleh orang tua angkat saat mengangkat anak. Tujuan adanya bimbingan bagi orang tua angkat adalah untuk membantu orang tua angkat dalam menghadapi masalah yang timbul ketika proses pengangkatan anak dan masalah pribadi yang dihadapi oleh orang tua angkat saat mengangkat anak dan sesudah mengangkat anak. Penelitian ini merupakan penelitian kualitatif. Dalam pengumpulan data, penulis menggunakan metode wawancara, observasi, dan dokumentasi. Sampel dalam penelitian ini berjumlah 7 orang dengan rincian 4 pasang orang tua angkat anak terlantar dan 3 konselor. Sedangkan yang menjadi objek penelitian adalah pelaksanaan Bimbingan Konselor Bagi Orang Tua Angkat Anak Terlantar dan Apa metode yang digunakan konselor dalam melakukan bimbingan bagi orang tua angkat . adapun analisis data yang digunakan adalah analisis deskriptif. Hasil penelitian bahwa pelaksanaan bimbingan konselor bagi orang tua angkat yang dilakukan konselor di Dinas Sosial Kota Bandar Lampung adalah dengan menggunakan metode langsung dengan teknik individual atau teknik kelompok dengan pendekatan Client-Centered Therapy yang melalui beberapa tahapan dalam bimbingan yaitu tahap penyululuhan, konsultasi, konseling, pendapingan dan pelatihan. Teknik individu dengan menggunakan bimbingan individu dan pendekatan Client-Centered Therapy. Dengan tujuan untuk membuka cara berfikir klien untuk mencapai realisasi diri yang optimal. Dengan adanya pelaksanaan bimbingan konselor dan diberikannya metode Client-Centered Therapy kepada orang tua angkat hal ini juga memberikan pengaruh baik kepada anak angkat dengan menjadikan anak angkat menjadi anak yang mandiri, percaya diri, sabar dan berkepribadian baik kepada orang tua dan masyarakat sekitarnya.
\end{abstract}

Kata Kunci: Bimbingan Konselor, Metode Client-Centered Therapy.

Copyright $\odot$ 2020, Universitas Muhammadiyah Metro| 133 


\begin{abstract}
Guidance for counselors is one of the ways in which the government provides assistance to prospective adoptive parents who will adopt children by means of dialogue, provides motivation to find solutions and achieve desired goals. This research was conducted because of the background of the many problems that arise during the adoption process and personal problems faced by adoptive parents when adopting a child. The purpose of guidance for adoptive parents is to assist adoptive parents in dealing with problems that arise during the adoption process of children and personal problems faced by adoptive parents when adopting children and after adopting children. This research is a qualitative research. In collecting data, the writer uses interview, observation, and documentation methods. The sample in this study amounted to 7 people with details of 4 pairs of adopted parents of abandoned children and 3 counselors. While the object of research is the implementation of Counselor Guidance for Adopted Parents of Neglected Children and What methods are used by counselors in conducting guidance for adoptive parents. As for the analysis of the data used is descriptive analysis. The results of the study that the implementation of counseling guidance for adoptive parents conducted by counselors in Bandar Lampung Social Service is to use direct methods with individual techniques or group techniques with the Client-Centered Therapy approach which goes through several stages in the guidance namely counseling, consultation, counseling, monitoring and training. Individual techniques using individual guidance and the Client-Centered Therapy approach. With the aim to open up the way of thinking of clients to achieve optimal self-realization. With the implementation of the counselor's guidance and the provision of Client-Centered Therapy methods to adoptive parents this also has a good influence on adopted children by making adopted children become independent, confident, patient and personable to both parents and the surrounding community.
\end{abstract}

Keywords: Counselor Guidance, Client-Centered Therapy Method.

\section{A. PENDahuluan}

Bimbingan menurut Prayitno, bimbingan adalah sebagai proses pemberi bantuan oleh seorang ahli kepada seorang atau beberapa orang individu baik anakanak, remaja, dirinya sendiri, dan mandiri dengan memanfaatkan kekuatan individu dan sarana yang ada dan dapat dikembangkan berdasarkan norma-norma yang berlaku (Amti, 2013).

Rochman Natawidjaja mengartikan bimbingan sebagai suatu proses pemberian bantuan kepada individu yang dilakukan secara berkesinambungan, supaya individu tersebut dapat memahami dirinya, sehingga dia sanggup mengarahkan dirinya dan dapat bertindak secara wajar, sesuai dengan tuntutan dan keadaan lingkungan sekolah, keluarga, masyarakat dan kehidupan pada umumnya. Dengan demikian dia akan dapat menikmati kebahagiaan hidupnya, dan dapat memberi sumbangan yang berarti kepada kehidupan masyarakat pada umumnya. Bimbingan membantu individu mencapai 
perkembangan diri secara optimal sebagai makhluk sosial (Yusuf dan Juntika).

Dari penjelasan diatas dapat dicermati bahwa bimbingan merupakan proses pemberian bantuan yang lakukan oleh seorang ahli dalam bidangnya dengan dasar keikhlasan dengan cara mengaplikasikan nilai-nilai yang ada didalam Al-Qur'an.

Konselor sendiri adalah pihak yang membantu klien dalam proses konseling. Sebagai pihak yang paling memahami dasar dan teknik konseling secara luas, konselor dalam menjalankan perannya bertindak sebagai fasilitator bagi klien (Lubis, 2013). Konselor adalah seorang yang efektif, perlu mengenal diri sendiri, sebagai klien, memahami maksud dan tujuan konseling, serta memahami proses konseling (Supriatna, 2011). Konselor merupakan pengampu pelayanan ahli bimbingan dan konseling. Bimbingan dan Konseling sebagai sebuah profesi digambarkan dengan tampilnya konselor yang dapat memberikan ketenteraman, kenyaman dan harapan baru bagi klien. Untuk menjadi seorang konselor professional haruslah menampilkan sikap hangat, empati, jujur, menghargai, dan yang paling penting dapat dipercaya (terjaga kerahsiaan konseli) (Sigit. 2006). Ada tiga isu sentral dalam mendiskusikan tentang kualitas pribadi konselor, yaitu : pengetahuan, keterampilan dan kepribadian. Dari ketiga hal tersebut kepribadian merupakan hal yang paling penting meskipun yang lain juga tak kalah pentingnya dan ketiganya merupakan satu kesatuan yang tak dapat dipisahkan (Cavanagh, 1982). Kualitas pribadi konselor merupakan faktor yang sangat penting dalam konseling.

Konselor menurut penulis adalah seseorang yang memahami dasar dan tehnik konseling dalam membina hubungan, dukungan serta memfasilitasi suatu perubahan klien secara profesional.

Orang Tua Angkat menurut Pasal 1 ayat (4) peraturan pemerintah No. 54 Tahun 2007, menjelaskan bahwa orang tua angkat adalah orang yang diberi kekuasaan untuk merawar, mendidik, dan membesarkan anak berdasarkan peraturan perundang-undangan dan adat kebiasaan. Anak Terlantar adalah anak yang berusia 5-18 tahun yang menghabiskan sebagian besar waktunya untuk mencari nafkah atau berkeliaran di jalanan maupun ditempat-tempat umum.

Pentingnya kehadiran seorang anak dalam suatu keluarga merupakan suatu amanah sekaligus karunia Tuhan Yang Maha Esa, bahkan anak dianggap sebagai harta kekayaan yang paling berharga dibandingkan harta benda laiinnya. Karenanya anak sebagai karunia Tuhan harus senantiasa dijaga dan dilindungi karena dalam diri anak melekat harkat, martabat, dan hak-hak sebagai manusia yang harus dijunjung tinggi.

Anak merupakan anugerah dan amanah yang diberikan oleh Tuhan Yang Maha Esa. Oleh karena itu anak sebagai amanah dari Tuhan harus senantiasa dijaga dan dilindungi oleh keluarga, masyarakat, dan negara karena di dalam diri anak melekat hak anak yang merupakan bagian dari hak asasi manusia yang termuat di dalam Undang-Undang Dasar 1945 dan Konvensi Perserikatan Bangsa Bangsa (PBB) Pada tahun 1989 tentang hak-hak anak. Undang-Undang No. 
39 Tahun 1999 tentang Hak Asasi Manusia telah mencantumkan tentang hak anak, pelaksanaan dan kewajiban orang tua, keluarga, masyarakat, pemerintah dan negara untuk memberikan perlindungan terhadap anak.

Maka demi pengembangan kepribadiannya anak secara utuh dan harmonis hendaknya tumbuh kembang dalam suatu lingkungan keluarga yang penuh kasih sayang dan pengertian. Menurut BPS (Badan pusat statistik) Kota Bandar Lampung tahun 2015 tercatat ada 1229 jumlah anak terlantar, hanya karena beberapa faktor, dan diantaranya adalah karena faktor ekonomi seperti kemiskinan. Merasa tidak sanggup untuk memenuhi hak-hak anaknya orangtua rela menyerahkan anak kandungnya ke panti asuhan karena takut tidak dapat memenuhi kebutuhan anaknya.

Dengan demikian figur orang tua angkat sangat dibutuhkan oleh anak-anak terlantar demi untuk menunjang tumbuh kembang anak serta memberikan rasa aman dan nyaman untuk anak yang akan mereka angkat. Disinilah peranan pemerintah untuk memberikan wadah bagi para calon orang tua yang akan mengangkat anak terlantar. Banyaknya kasus yang disebabkan oleh kurangnya pengawasan, pembekalan serta bimbingan yang diberikan oleh pemerintah membuat tidak sedikit anak terlantar mendapat perlakuan tidak menyenangkan dari keluarga baru mereka.

Bimbingan Konselor Bagi Orang Tua Angkat Anak Terlantar adalah salah satu program Kementrian Sosial yang dilaksanakan di setiap Dapartemen Sosial di Daerah. Tujuan dari Bimbingan Konselor
Bagi Orang Tua Angkat Anak Terlantar sendiri adalah memberikan bantuan baik secara psikis ataupun non psikis serta sebagai pendampingan untuk calon orang tua angkat, hal ini dikarenakan banyaknya Orang Tua Angkat yang masih bingung dan cemas mengenai prosedur untuk pengangkatan anak dan masalah lainnya sehingga diperlukannya pembimbing untuk membantu para Orang Tua Angkat. Dengan demikian sangat perlu untuk mengetahui sejauh mana keberhasilan Bimbingan Konselor Bagi Orang Tua Angkat Anak Terlantar di Dinas Sosial Kota Bandar Lampung.

Lembaga Dinas Sosial Kota Bandar Lampung memiliki pegawai dan konselor yang berkompeten dibidangnya. Oleh sebab itu peneliti sangat tertarik untuk melakukan penelitian di Lembaga Dinas Sosial Bandar Lampung.

\section{B. METODE PENELITIAN}

Pendekatan yang digunakan dalam penelitian ini adalah kualitatif deskriptif merupakan suatu metode dalam meneliti status sekelompok manusia, suatu objek, suatu set kondisi, suatu system pemikiran, ataupun suatu kelas pristiwa pada masa sekarang. Dalam penelitian ini metode atau alat pengumpulan data yang digunakanan untuk menghimpun data, antara lain adalah metode observasi, metode wawancara dan metode dokumentasi.

Subjek penelitian adalah suatu hal atau orang yang digunakan sebagai sumber penelitian. Pengambilan subjek penelitian ini menggunakan Non Random Sampling yaitu pemilihan subjek dari sample yang ada didalam populasi. 
Metode penelitian yang digunakan adalah metode kualitatif yaitu cara-cara penelitian yang sistematis dan logis untuk memecahkan suatu permasalahan, pendekatan yang digunakan kualitatif deskriptif, tujuan dari kualitatif deskriptif yaitu untuk membuat deskripsi, gambaran, atau lukisan secara sistematis, faktual, dan akurat mengenai fakta-fakta, sifat-sifat serta hubungan antar fenomena yang diselidiki. Dan penulis mengumpukan data menggunakan metode pokok yaitu observasi di dalam observasi terhadap observasi (non partisipan) dengan alat-alat pendukung pengumpulan data seperti wawancara dan dokumentasi, disini juga penulis mengambil subjek penelitian menggunakan Non Random Samping (Bachtiar, 1997).

Jenis penelitian ini adalah penelitian lapangan dengan pendekatan kualitatif, datadata yang diperoleh dari penelitian ini disampaikan atau disajikan dalam bentuk kalimat-kalimat. Sedangkan penelitian ini adalah usaha untuk menemukan, mengembangkan dan menguji kebenaran suatu pengetahuan, yang digunakan dengan metode-metode ilmiah (Hadi, 1989). Strauss menyatakan bahwa penelitian kualitatif adalah suatu jenis penelitian yang menghasilkan temuan-temuan yang tidak diperoleh oleh alat statistik atau alat-alat kuantitatif lainnya (www.liguistikid.blogspot.co.id 2018) Oleh karena itu peneliti menggunakan metode kualitatif agar dapat menghasilkan data yang lengkap melalui uraian mendalam tentang ucapan, tulisan yang diamati berkaitan dengan Bimbingan Orang Tua Angkat
Terhadap Anak Terlantar di Lembaga Dinas Sosial Bandar Lampung

Penelitian ini bersifat studi kasus. Penelitian studi kasus mempelajari secara intensif seseorang individu atau kelompok yang dipandang mengalami kasus tertentu (Trianto, 2010). Jadi penelitian yang bersifat studi kasus merupakan penelian yang melibatkan populasi sebagai sumber data yang terbatas namun masalah yang diselidiki semakin mendalam suatu program, kejadian, atau aktifitas, proses atau seseorang individu atau lebih.

Populasi adalah keseluruhan dari jumlah subyek yang diteliti, populasi disebut juga univers tidak lain dari daerah generalisasi yang diwakili oleh sampel. Dalam penelitian ini skripsi yang mengenai Bimbingan Orang Tua Angkat Terhadap Anak Terlantar Di Lembaga Dinas Sosial Bandar Lampung adapun yang menjadi populasi dalam penelitian ini adalah berjumlah 3 orang konselor dan 8 Orang Tua Angkat dan Orang Tua Angkat yang mengangkat Anak Terlantar Berjumlah 4 orang.

Sampel adalah kelompok kecil yang diamati dan merupakan bagian dari populasi sehingga sifat dan karakteristiknya populasi juga dimiliki oleh sampel.

Secara teknis dalam penarikan sampel, teknik yang digunakan purposive sampling yaitu sampel yang dilakukan dengan mengambil orang-orang yang terpilih oleh peneliti menurut ciri-ciri spesifik yang dimiliki.

Adapun yang dimaksud penelitian ini keseluruhan berjumlah 7 orang dengan rincian : 4 orang tua angkat anak terlantar, 
dan 3 konselor informasi dalam penelitian ini adalah ibu Evazati S. Sos (Staf pelayanan sosial anak)

\section{PEMBAHASAN}

Berdasarkan data yang di peroleh dari penelitian pada kegiatan bimbingan konselor bagi orang tua angkat di Dinas Sosial Kota Bandar Lampung, peneliti melakukan pengamatan dan wawancara dengan orang tua angkat yang melakukan bimbingan. Dari hasil penelitian diketahui bahwa bimbingan bagi orang tua angkat di Dinas Sosial Kota Bandar Lampung sangat berpengaruh bagi orang tua angkat.

Dalam proses bimbingan konseling ini, seperti yang dijelaskan bahwa Orang tua angkat akan melakukan bimbingan di Dinas Sosial Kota Bandar Lampung dengan melalui beberapa tahap yaitu antanya tahap penyuluhan, konsultasi, konseling, pendampingan dan pelatihan. Apabila didalam proses bimbingan berlangsung terjadi masalah yang dialami orang tua angkat maka konselor akan memberikan Motivasi untuk menguatkan orang tua angkat dan konselor juga biasanya menggunakan pendekatan Client-Centered Therapy, disini klien diajak berdialog dengan konselor dalam memecahkan masalah yang dihadapi oleh orang tua angkat pada pendekatan ini bertujuan untuk memberikan gambaran diri klien yang ideal dengan keadaan yang sebenarnya. Hal ini dilakukan juga untuk memotivasi klien dalam pengangkatan anak. Jika klien sudah melewati semua tahapan di atas. Maka klien mengembangkan diri, memantapkan hati dalam mengangkat anak.
Menurut analisa penulis, tahapan dan metode ini termasuk sebagai salah satu pendukung untuk memotivsi orang tua angkat dalam hal mengangkat anak dan pemecahan masalah yang mereka hadapi, dengan adanya tahapan dan metode ini orang tua angkat kini dapat mengasuh dan membimbing anak-anak terlantar dengan hasil menjadikan anak-anak yang mereka angkat menjadi anak yang lebih percaya diri, sabar dan mandiri baik dalam lingkungan keluarga maupun masyarakat.

\section{KESIMPULAN}

Berdasarkan hasil analisis yang penulis uraikan dalam BAB sebeumnya, maka dapat ditarik kesimpulan bahwa metode bimbingan konselor yang dilakukan oleh konselor di Dinas Sosial Kota Bandar Lampung adalah dengan metode langsung (face to face) bertemunya konselor secara langsung secara bertatap muka dengan klien. Tahapan bimbingan bagi orang tua angkat yang harus dilalui adalah penyuluhan, konsultasi, konseling, pendampingan dan pelatihan. Metode langsung digunakan dengan teknik individual yang dilakukan dengan bimbingan individu digunkan dengan pendekatan Client-Centered Therapy yang bertujuan unutk memperbaiki dan mengubah sikap, presepsi cara berfikir, keyakinan serta pandangan klien yang irasional menjadi rasional, sehingga dia dapat mengembangkan diri dan mencapai realisasi diri yang optimal serta melatih dan mendidik klien agar dapat menghadapi kenyataan hidup secara rasional dan membangkitkan kepercayaan diri, nilainilai, dan kemampuan diri sehingga mampu membentuk kepribadia anak-anak terlan 
ar menjadi lebih percaya diri, sabar dan mandiri.

\section{E. DAFTAR PUSTAKA}

Supriatna, Mamat. (2011), Bimbingan Dan Konseling Berbasis Kompetisi, Jakarta: Raja Garafindo Persada.

Lubis, Namora Lumangga. (2013).

Memahami Dasar-Dasar Konseling

Dalam Teori dan Praktik, Jakarta: Kencana.

Prayitno, Erman Amti. (2013). Dasa -Dasar Bimbingan dan Konseling, Jakarta : Rineka Cipta.

Sanyata, Sigit. (2006). Perspektif Nilai

Dalam Konseling: Membangun Interaksi Efektif antara Konselor Klien. Jurnal: Diterbitkan pada Jurnal Paradigma,No. 02 Th. I, Juli 2006 ISSN 1907-297X Universitas Negeri Yogyakarta

Sutrisno Hadi, (1989). Metode Riset jilit I-II Yogyakarta: Andi Ofset.

Syamsu Yusuf dan Juntika Nurihsan, Landasan Bimbingan dan Konseling, Bandung:Remaja Rosdakarya.

Cavanagh, ME. (1982). The Counseling Experience: A Theoretical and Practical Approach. Monterey. California: Brooks/Cole Publishing Company.

Trianto. (2010). Pengantar Penelitian

Pendidikan bagi Pengembangan

Profesi Pendidikan Tenaga Pendidikan, Jakarta : Kencana.

Undang - undang Nomor 54 tahun 2007, Peraturan Pemerintah, Pasal 1 ayat(4).

Wardi Bachtiar. (1997). Metodologi Penelitani Ilmu Dakwah, Jakarta, Logos Wacana Ilmu.
Sumber Internet :

https://www.liguistikid.blogspot.co.id.metop

en. 